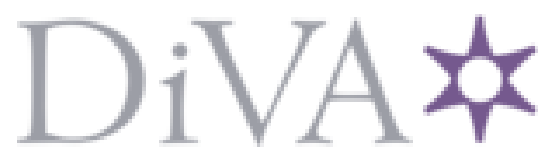

http://www.diva-portal.org

\title{
Postprint
}

This is the accepted version of a paper presented at Academic MindTrek 2015, 22-24 September 2015, Tampere, Finland.

Citation for the original published paper:

Nyström, T., Mustaquim, M. (2015)

Universal Design as a Cause of Triggering Innovation Levels for Sustainability-A Deliberative Concept.

In: Turunen, M (ed.), Proceedings of the 19th International Academic MindTrek Conference (AcademicMindTrek '15) (pp. 114-121). New York: Association for Computing Machinery (ACM)

http://dx.doi.org/10.1145/2818187.2818279

N.B. When citing this work, cite the original published paper.

Permanent link to this version:

http://urn.kb.se/resolve?urn=urn:nbn:se:uu:diva-261096 


\section{Universal Design as a Cause of Triggering Innovation Levels for Sustainability-A Deliberative Concept}

\author{
Tobias Nyström \\ Uppsala University \\ Uppsala, Sweden \\ tobias.nystrom@im.uu.se
}

\author{
Moyen M. Mustaquim \\ Uppsala University \\ Uppsala, Sweden \\ moyen.mustaquim@im.uu.se
}

\begin{abstract}
Sustainability achievement through design could be seen as a connective result of design and innovation. The role of universal design (UD) for sustainability is well known, although how any innovation through this could be produced by the practice of UD is not evident. Different innovation levels could be triggered positively towards sustainability by practicing UD in an advanced way. In this paper, different innovation levels associated with sustainability achievement were scrutinized within the scope of UD. It was presented how the advance perspective of UD could have a direct impact on incrementing innovation levels of organisations, thereby ensuing sustainability. The advance concept of UD was then revisited in a deliberative way to justify the argument of the extensiveness of UD beyond the traditional scope of the accessibility domain only. Finally, the concept of sustainable human-computer interaction (HCI) was also re-explored within the context of UD and its practice.
\end{abstract}

\section{Categories and Subject Descriptors}

H.5.m. [Information interfaces and presentation (e.g., HCI)]: Miscellaneous.

\section{General Terms}

Design, Theory.

\section{Keywords}

Sustainability; Innovation Triggering: Design Process; Universal Design.

\section{INTRODUCTION}

Innovation is an omnipresent discussion topic of modern society. This, to some extent, could be due to the constantly changing nature of technologies existing in our everyday life.

"Copyright is held by the owner/author(s), 2015. Publication rights licensed to ACM. This is the author's version of the work. It is posted here by permission of ACM for your personal use. Not for redistribution. The definitive version was published in AcademicMindTrek '15, September 22 - 24, 2015, Tampere, Finland http://doi.acm.org/10.1145/2818187.2818279".
Improvement and introduction of new products have often been one of the primary concerns and worries in most western countries [19]. Innovation is a highly contextual concept, although a common denominator of different innovation definitions is their primary focus on the success of the end product. Likewise, sustainability is not a new conception in today's world, and it reflects circumstantial meaning and is closely related together with innovation and its associated designs. Innovation is not a straightforward process, and consequently does not happen radically as a single segment complex process, but rather it has different degrees, and based on these degrees, innovations could be categorised in different levels. Proper understanding of the appropriate levels of innovation can lead towards the success of a specific innovation's application. This is because innovation for organisations is not limited to the improvement of a particular design or making something unique, but instead, it can also point out novel changes of the organisational structure and different inter-organisational process associated with product development [7]. In the design community, UD has been popularly known as a design philosophy for accessible design. It has also been acknowledged to be a key component of sustainable design, and it is often stated that the twenty first century design needs to be universal for being sustainable, and vice versa. Advanced ways of looking into UD for accomplishing sustainability is evident in the work of Mustaquim and Nyström [23,26]. As design and innovation is connected to sustainability achievement, it is valuable to explore how different innovation levels associated with sustainability achievement could be triggered by UD and its advanced concept. This leads to the underlying research question of this article, "How can UD influence organisation's design strategies towards innovations for sustainability?" In an attempt to answer this research question, the different innovation levels associated with sustainable design were explored within the context of UD and a theoretical framework was then formed. The proposed framework has resulted in analysis of seven design principles of UD for triggering innovation for sustainability. This constitutes a proposed model of theory construction from other perspectives that Friedman accentuated as one future direction for design theory development [15]. The result was then revisited retrospectively for a deliberate understanding of sustainable HCI by UD and its advanced notion.

The paper is divided into six sections. After this Introduction section, a brief Background is presented discussing UD, innovation, and sustainability. The theoretical framework of innovation levels presented and discussed in section 
three, An innovation level framework for sustainability. Section four, HCI and Sustainability through Design, discussed the new knowledge that could be taken from the result of this article in the study of sustainable HCI followed by a discussion and looking at future work possibilities in Discussions and Future Work. The paper is finalised in the Conclusions section.

\section{BACKGROUND}

\subsection{Universal Design and its Advanced Concept}

Design in itself could be seen as a process that changes the current situations into preferred ones [34]. The design process often crosses many domains and often ambiguous inquiries, as design theory is an integrative and interdisciplinary discipline [15]. Therefore, UD could be important in the design process of sustainability. UD was shaped as an answer to changes in demography; since people live longer, more people live with disabilities, and these limitations require the design and construction of environments and products with regard to the need and rights of all citizens [36]. The principles of UD were developed by "The Center for Universal Design" and consist of seven design principles: "Equitability in Use", "Flexibility in Use", "Simple and Intuitive Use", "Perceptible Information", "Tolerance for Error", "Low Physical Effort", and "Size and Space for Approach and Use" [36]. Hitherto UD was primarily focusing on design for disabled and impaired people, but Mustaquim and Nyström [23] has expanded the concept from the governing focus on accessibility by integrating it into the design of sustainable IT systems. UD was further used by Mustaquim and Nyström $[24,26]$ in designing information systems aiming for sustainability, and furthermore in the development of an open sustainability innovation framework. Another advanced way of viewing UD in HCI is to take classical HCI theories and design philosophies like UD into consideration for accomplishing sustainable actions [25]. The versatility of UD is thus manifested as an advanced and valuable concept. The notion of UD used in this paper is therefore to point out its progress further beyond the traditional scope of accessibility.

\subsection{Innovation}

Companies can either adapt to change or initiates innovation and create havoc to existing structures and equilibrium of different markets. The start and pioneering of innovation theory is usually credited to Joseph Schumpeter, who in the 1920s defined innovation as outputs such as, new goods or a new quality of goods, a new organisational structure (e.g. mergers), opening up new markets, a new method of production, or a new source of supply [32]. Innovation is one of the three factors of technological development, while the other two are invention and diffusion. Invention happens when something is invented for the first time compared to innovation where existing things could be used or combined in a new way. On the other hand, diffusion refers an adoption that is necessary for an innovation. What becomes clear is the distinction between invention and innovation: where the former is not dependent on the latter but the latter might include the former. Thus, an invention does not have to be adopted and become an innovation, although many people still confuse invention with innovation [13]. The definition of innovation is not conclusive and varies with context, e.g. Everett Rogers [30] a pioneer in the diffusion and adoption theory defined innovation as an idea, practice or object perceived as new by the individual or other unit of adoption.

A citation from Schumpeter [32], "But if innovation consists in the introduction of a new commodity, the entrepreneur finds himself, as we have seen, almost invariably in an imperfectly competitive situation." emphasizes that innovation could give a competitive advantage. In a world where competitive advantage is seen as more difficult to sustain [1] innovation could be one source of competitive advantage. In an increasingly changing and competitive world, innovation is seen as a critical factor to gain competitive advantage [38].

A characteristic that is often recognized and displayed in innovation theory is different innovation typologies reflecting mainly the differences between incremental innovation and disruptive innovation [4,21]. In Garcia and Calantone's [16] review of technological innovation, a few more typologies were mentioned (Really new innovations, Discontinuous innovations, and Imitative innovations). They also notified that, typologies like incremental and radical are defined in numerous fashions depending upon from whose perspective innovativeness is being evaluated. Typologies of innovation are often focused on the newness of the technology, versus newness to the market and one example is seen in Chandy and Tellis $[3,4]$ whose typology is further explained and used in section Universal Design as a Cause of Innovation Trigger.

\subsection{Incremental vs Radical Innovation}

To summarize, incremental innovation compared to radical innovation:

Incremental innovation is based on iterative efforts to provide new benefits, features, and improvements to products in the existing market based on existing technologies (i.e. improvements within a given frame of solutions [28]). Examples of incremental innovation are improvements in the fuel efficiency of the combustion engines in vehicles, or technological improvements that make it possible to extract oil whereas it was previously not possible.

The roots of radical innovation can be derived from Schumpeter [33] who proposes "creative destruction", where innovations destroy the market positions of businesses that commits and sticks to old technology. A radical innovation is, in this paper, seen as innovations based on new technology that through discontinuity results in a novel market infrastructure. One example is from the 1970s to the 1980s, when Facit, a global Swedish company offering office products such as typewriters and calculators based on mechanical technology faced new competition from semiconductor based products (electric calculators and typewriters), that later transformed into computers. Same thing happened to Kodak when photography changed from products based on chemical technology to digital technology or when the distribution of music and movies changed from physical (CD, VHS, and DVD) to digital distribution via internet i.e. download or streaming services (e.g. Netflix, iTunes, and Spotify). Important to note is that the rule on how to distinguish a radical innovation is delicate, since there are no scales on how to measure the radicalness of an innovation [16], and what threshold of radicalness must an innovation pass in order to be labeled as a radical innovation.

Another very popular typology of innovation is disruptive 
innovation, which originally was based on disruptive technology $[2,5]$, but later expanded to include disruptive innovation based on business-model innovation or product innovation [20]. Innovations are disruptive to incumbents because they dramatically disrupt the current market compared to sustaining innovation that does not affect the market. One interesting point is that disruptive innovation per se. do not have to be disruptive, depending on the diffusion pattern of the new product [31]. Christensen et al. [6] thus sees disruptive innovation in the form of "Catalytic Innovation" to be a solution to problems that calls for a social change. The interesting thing with disruptive innovation is that like radical innovation it does not have to more or less totally eradicate other innovations, e.g. Amazon's disruptive business model has not eradicated old-fashioned bookstores.

\subsection{Innovation and Sustainability}

Sustainability is an imminent problem facing human society today and thus research on sustainability is now a hot research topic and conducted in different research fields [29]. Our perception of sustainability is primarily based on the world commission on environment and development's definition: "that it meets the needs of the present without compromising the ability of future generations to meet their own needs" [39]. We also recognize the complexity of sustainability as a social challenge that encompasses ethical dilemmas and an impact that could affect future generations and thus a multidimensional analysis and holistic view is necessary to contemplate [29]. Other problems that need to be tackled are: today a human centered perspective is dominant in sustainability research, another issues is how to deal with changes of desirable sustainability goals due to alterations of accrued knowledge. Different actors also have different preferences and cognition on what constitutes important sustainability issues, and thereby rank problems and solutions differently e.g. while one group advocates wind power, another group could perceive wind power as something that destroys the environment by killing birds.

As innovation is recognized to be a way of developing competitive advantages and to disrupt the current market, it is natural to see innovation as a strong force that could be used to achieve sustainability. Innovation as a solution to solve the problems of sustainability can be seen in Christensen et al. [6] who attempted to use disruptive innovation as a solution to problems that needs social change. This view is shared with Freeman [14] who acknowledges that incremental improvements of existing systems will not be enough e.g. to achieve the scale of reduction in energy and material consumption that is needed to reach sustainability calls for radical innovations that includes new industrial, construction, and transport systems.

To make people consider the benefits of innovation, marketing is an excellent facilitator. Marketing of the innovation is essential since we have seen that the disruption started by disruptive innovation is dependent on the adoption and diffusion pattern of the innovation. Unfortunately, today much marketing of innovation that is aimed towards sustainability could be seen as greenwashing e.g. in Sweden oil companies use incremental (i.e. sustaining) innovation by reducing a little carbon dioxide emitted from the use of diesel and petrol fuel, and then want their customers to see the company and its product to be eco-friendly. Nidumolu et al. [27] showed that reduction of raw material inputs together with new and
Table 1: A typology matrix of innovation based on Chandy and Tellis $[3,4]$

\begin{tabular}{|c|c|c|c|}
\cline { 3 - 4 } \multicolumn{2}{c|}{} & \multicolumn{2}{c|}{$\begin{array}{c}\text { Customer benefit } \\
\text { (need fulfillment) }\end{array}$} \\
\cline { 3 - 4 } $\begin{array}{c}\text { Newness of } \\
\text { technology }\end{array}$ & Low & Low & High \\
\cline { 2 - 4 } & High & $\begin{array}{l}\text { Technomental } \\
\text { breakthrough }\end{array}$ & $\begin{array}{c}\text { Market } \\
\text { Breakthrough }\end{array}$ \\
\hline
\end{tabular}

better products and new markets could give higher profit and thus concluded that sustainability is a source for organisational and technical innovation. They perceived that companies embracing sustainability today would gain a competitive advantage that will be difficult for competitors who ignore sustainability to catch up with later.

\subsection{Universal Design as a Cause of Innovation Trigger}

If matched correctly, it should be possible to use the design principles as a trigger for an innovation level, i.e. UD principles can catalyze an identified innovation level. In Table 1 we used the typology from Chandy and Tellis [3,4] where "Newness of technology" denotes to what level a new product or service use of technology is different from earlier technologies, and "Customer benefit (need fulfillment)" refers to what level the new product or service fulfills customer needs better than existing products or services.

So UD can either essentially trigger the market or the technical aspect of different innovations. When looking at the history of mature technology at some point a new technology emerges, but initially the new technology's benefits are inferior to the existing one [4] (although new product based on the new technology could be considered a technological breakthrough). An example of this could be when the new product is very expensive or initially have limited use; the first phones had very little benefits but increased with the spread and adoption of this innovation. In this case, UD principles could be used as triggers that makes the innovation possible and reach the technical breakthrough. Nevertheless, with more research and development, products based on the new technology will start to improve consumer benefits rapidly, and at one point in time it will surpass the old technology [4] (here also UD triggers can make the transition into this innovation phase possible), e.g. the digital camera. When this happens, the product based on the new technology becomes a radical product innovation. The threat from the new technology brings supporters of the old technology into making improvement efforts that might produce some product improvements. (this could represent just an incremental innovations or be a market breakthrough), and could mainly be triggered by other UD principles. An example of this is when Kodak continued their development of traditional cameras and tried to find and fulfill needs on niche markets. Since the improvements of the old technology cannot keep pace with the much faster rise of the new technology, it will finally be replaced by the dominant technology. While not every technological breakthrough turns into a radical innovation, it does have the potential to make existing products obsolete [3] and UD's potential in this regard could thus be seen as a trigger. 


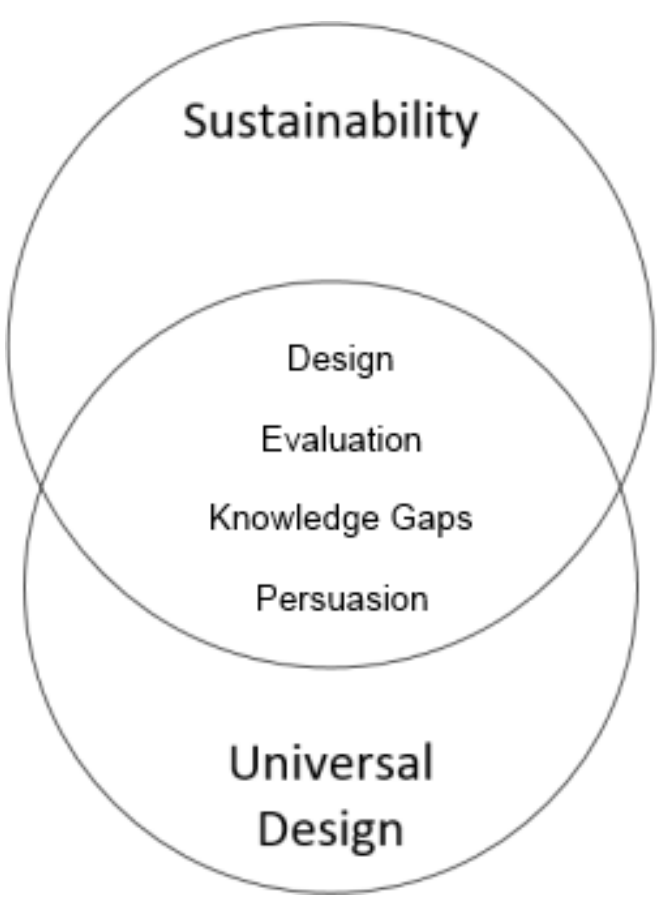

Figure 1: Universal design space for sustainability.

\section{AN INNOVATION LEVEL FRAMEWORK FOR SUSTAINABILITY}

As described in section Innovation there exists several different classifications of innovations e.g. typologies. However, there are several other types of innovations used by economists and psychologists. For instance, the literature review by Coccia [8] reveals several taxonomies of innovation used by management of technology. It's important to realize here is as revealed previously, the notion of innovation is contextual in nature, the innovation categories that are associated with design aiming for sustainability are of concern in this paper. Also, as seen in section Innovation it was stated that product and market innovation has importance in sustainability through design. It would thus be wise to explore different innovation levels within the context of these addressed innovations types. In this section, we describe the relevant degrees of innovations in brief, with UD as a trigger for different innovation levels aiming for sustainability.

There exist different models that are trying to capture the complexity and multidimensionality of sustainability [29] and one of them is the triple bottom line (TBL) by Elkington [11]. The three components of TBL: society, economy, and the natural environment were focused on a sustainability context to address different challenges that could be solved by using UD. TBL defines sustainability to include its three components and how innovations of different levels could take place on each of these components and their associated issues through the advanced HCI design practice of UD were the focus. The tasks of achieving sustainability were divided into three different subtasks, namely: "Designing sustainable systems", "Evaluating the sustainability of the systems", and "Motivating users to participate in the use of systems". The identified challenges were thus design, evaluation, knowledge gaps and persuasion which were illustrated in Figure 1 as a design space for sustainability and UD. To discourse the three addressed tasks these challenges were then discussed with the perspective of the elements of TBL and the implication of UD.

\section{Design}

Designing a system could be thought from several different perspectives while considering sustainability. A system could be designed to achieve sustainable actions through its use. A system itself could be sustainable in nature which over time would act sustainably. A system development process could also be sustainable by reducing, updating or adding/removing components cost. Having a heuristic or a collective view on what system design actually implies could help in understanding what properties a system should require for its users. UD could play an important role in this kind of global and generalized identification of system requirements. UD principles could be used to understand user requirements which could trigger improved system design. UD could contribute for playing a holistic role in understanding what components are important for a system to increase its influence on social, economic and natural environment during its use. For example, the design of a system aiming for social sustainable actions should be compliant while economic sustainability should focus on flexibility. Users of a system designed for environmental sustainability elevation should, on the other hand, be able to use the system with minimal effort needed. These requirements can be better defined while UD is applied.

\section{Evaluation}

Evaluation is a major and complex challenge for sustainability and HCI can play a crucial role in this. UD could be used as a measuring parameter for sustainability in this regard. While no strong method exists to evaluate UD itself, different assessment methods are being developed for UD (e.g. see Mustaquim and Nyström [22]). These approaches could be used to assess different factors of sustainability reflected in the context of UD. "Can a design truly be called sustainable if it is not universally designed, and vice versa?" is an interesting interrogation to raise the motivation towards evaluation using UD. Error reduction in the evaluation process, low effort in complex calculations involving economy and intuitive approach for social sustainability are some of the example parameters from UD that could be thought as an assessment resolution of sustainability. Need assessment, benchmarking, and requirements for redesign of a system could also be done from diverse perspectives when UD philosophies are considered and applied.

\section{Knowledge Gaps}

UD could be a powerful technique for filling the gap of knowledge in sustainability research. Different features of UD principles could be considered in social, economic and environmental frameworks to categorize gaps in sustainability research for different sets of users. From an economic perspective, UD could be used to initiate product or process innovation by involving a wide range of different users to create significant competitive benefits for companies. Better approachability through design for understanding the social sustainability problems, easy perception of economic issues through the designed system to resolve cost-effective sustainability issues, and promotion of equitability for understanding environmental sustainability problems. These could be some instances of how UD could be used to gen- 
Table 2: A framework of innovation levels for sustainability

\begin{tabular}{|c|c|c|c|c|}
\cline { 2 - 5 } \multicolumn{1}{c|}{} & \multicolumn{4}{c|}{ Innovation technology } \\
\cline { 2 - 5 } \multicolumn{1}{c|}{} & Incremental & $\begin{array}{c}\text { Market } \\
\text { breakthrough }\end{array}$ & $\begin{array}{c}\text { Technical } \\
\text { breakthrough }\end{array}$ & Radical \\
\hline $\begin{array}{c}\text { UD } \\
\text { trigger }\end{array}$ & P2, P5 & P1 & P7 & P3, P4, P6 \\
\hline
\end{tabular}

erate new knowledge in sustainability research. Since the process of practicing UD is equally important as the resulted end product [18] it can be practiced in a legitimate way for adding new epistemological values in sustainability research. Understanding moral or ethical status of an organisation, strategic influence of business, improved description of markets and products or services, etc. could also be realized in an amended way by practicing UD in the design for sustainability cases.

\section{Persuasion}

One of the key purposes of design towards sustainability is to persuade its users in the direction of sustainable action. A relatively new research field titled "sustainable HCI" has initiated from this perception $[9,10]$. UD could be used to expose a new dimension in persuasion by expanding its traditional concept by adding new values in generating new design principles for persuasive design. For instance, understanding simplicity, intuitiveness and reduced effort during the use of a persuasive system could be re-defined by means of further developed principles and thoughts from UD perspective which in turn could help in developing a new cognitive model for persuasive design.

Figure 1 shows how UD and sustainability could be conceptualized as an intersection model where the four identified challenges are overlapped between the two addressed domains of sustainability and UD. Since the identified four challenges could be common entities for both design domains, it could be stated that practicing UD should contribute in understanding these challenges for defining sustainability and vice versa.

Now when it could be reasonable and justified to say that UD can be a key tool for sustainability achievement, we use the seven principles of UD to formulate a framework of innovation. In Table 2 each innovation level of sustainability is matched with UD principles that could trigger that particular innovation level. Seven design principles were marked as, P1 = Equitable Use, P2 = Flexibility in Use, P3 = Simple and Intuitive Use, P4 = Perceptible Information, P5 = Tolerance for Error, $\mathrm{P} 6=$ Low Physical Effort, and P7 $=$ Size and Space for Approach and use. The aspects of the seven design principles of UD that were identified to be important in triggering the four levels of innovation for sustainability with the help of UD space for sustainability and its context (Figure 1) are therefore described below.

\section{P1 - Equitable Use}

The design should be useful and marketable to people with diverse abilities. Therefore, the persuasion challenge that the innovation poses needs to be resolved in order to make users aware of all benefits of the innovation. This could trigger the market breakthrough since the established product can be changed into becoming more sustainable and therefore get larger market shares, capture a market niche, or improve the company's value (being perceived as a good and caring company). For example, when the prices of cars become affordable then there will be plenty of models to choose from depending on the consumer's need.

\section{P2 - Flexibility in Use}

The design should accommodate a wide range of individual preferences and abilities. This is an important design challenge since the design must be able to effectively and efficiently cope with updates and modifications that are demanded from a continuously changing world. Incremental e.g. new models and variations that satisfy different user preferences could thus be offered. A trigger would make it possible for more people to use the sustainable product or services offered, and also new markets could be discovered.

\section{P3 - Simple and Intuitive Use}

Use of the design should be easy to understand, regardless of the user's experience, knowledge, language skills, or current concentration level for triggering the radical innovation, e.g. the microcomputers that once was built by enthusiast became standardized and could be bought ready-made. It is also a major design challenge because the innovation must be versatile due to the differences between users. This trigger is essential if a product will leap from the technological breakthrough into becoming a radical innovation, since most users would want a product that is simple to use and the benefits are easy to perceive. The innovation for sustainability, therefore should be built to accommodate different knowledge levels, preferred cognition modes and learning styles.

\section{P4 - Perceptible Information}

The design should communicate necessary information effectively to the user, regardless of ambient conditions or the user's sensory abilities. This should be considered as a design challenge since the information given into and generated by the sustainable innovation must be accurate otherwise users will not trust and adopt the innovation.

\section{P5 - Tolerance for Error}

The design should minimize hazards and the adverse consequences of accidental or unintended actions. This is an evaluation challenge since different aspects and features of the innovation must be considered and measured in some way to find the best means to move forward. This triggers the incremental innovation, e.g. product becomes safer to use like modern cars that have more and more safety built-in. This trigger could make the product more sustainable since some risk and dangers of using a product would be avoided, e.g. dangerous and non-sustainable materials would be replaced and for the car example the vehicle becomes safer to drive (but will never be foolproof from accidents).

\section{P6 - Low Physical Effort}

The design should be used efficiently and comfortably and with a minimum risk of fatigue. Impact on radical innovation, e.g. the cellular phone became truly portable and thus became a market success. This is a design challenge because the minimum requirement that the users will have on the sustainable innovation must be understood and is vital since a sustainable innovation that is not used without a 
minimum of fatigue will probably not be used at all i.e. no adoption will occur. In that case, it would not matter if a product or service were superior when comparing sustainability and/or other features unless adoption by the market occurs.

\section{P7 - Size and Space for Approach and Use}

Appropriate size and space should be provided for approach, reach, manipulation, and use, regardless of user's body size, posture, or mobility. This would deal with the knowledge gap challenges since a given design space cannot exist until the underlying sustainable technology becomes available. This would have an impact on the technological breakthrough, e.g. semiconductors/microprocessors enabled a move from mechanical to electronic machines. This trigger will make it possible to offer customer either by technology or market inventions, to use products or services that were previously impossible to design. Much of the new technology makes things more effective and efficient and thus should reduce the need for resources, thereby be more sustainable.

\section{HCI AND SUSTAINABILITY THROUGH DESIGN}

The design process is fundamental for the consequent characteristics of a constructed artefact. Design is essential since poorly designed industrial systems, buildings, products and services can greatly influence towards social and environmental degradation [35]. A socio-technical system is not limited to technical implications, but also has an impact on user practices, policies, market and cultural meanings [17]. HCI entails socio-technical systems since the system artefact and its interaction do not only have technical implications. It is established that as we interact with the system the system has an impact on us and can change our behavior [12]. Therefore, in a system design we also have an opportunity to build an artefact aimed to deliver a certain service for its users, taking an attempt to make them act in specific ways [12].

Nowadays we are surrounded by socio-technical systems, the interaction between computer and human being becomes more important. Because there are more systems to interact with, and we have limited capacity, we cannot put too much effort and time into learning how to interact efficiently with the machine. Thus the designing of humancomputer/machine interaction becomes utmost crucial as a success factor in order to achieve a successfully implemented system. Failure in understanding the design process is sometimes the cause of design failure [15], the developed framework could in this way help the designer. If carefully planned and designed then the use of UD principles as trigger should be able to catalyze innovation success in our previously different identified typologies and would increase the chance of successful innovation adoption. Thus, an ultimate goal would be to see innovation infused by the system, leading towards a radical change to be able to drive society and individual's actions towards sustainability goals.

Implying UD for sustainability is a novel way of exploring sustainability topics where this approach could be seen as a contribution from HCI on sustainability research and takes it one-step ahead. "How universal UD itself really is?" is an interesting question often asked for assessing the trustworthiness of the notion universal or universality in design. Expanding the concept of UD from its traditional view to- wards a research domain like sustainability thus reinforces the tangible meaning of UD. One good starting point of UD and sustainability research could therefore be to develop design principles in additional research domains dealing with sustainability. The further expansion of the UD concept and its principles in this paper to trigger different innovation levels of sustainability could be seen as opening up a new dimension i.e. to view sustainable HCI research area from an improved point of view.

\section{DISCUSSIONS AND FUTURE WORK}

The four identified challenges addressed in this paper (Figure 1) were the outcome of sustainability achievement rationale for social, economic and environmental spheres of Elkington's [11] triple bottom line of sustainability surrounded by the context of UD and its practice towards innovation. However, the change of attitude towards looking into UD beyond its traditional understanding has started its progress from a very abstract level. It is thus difficult to state that the identified four challenges are the only possible encounters attained by the practice of UD. On the other hand, extension of UD could solve other sustainability issues too, which were not the emphasis of this paper. The notion of universal access based on UD concept has started to spread beyond its usual concept. Frameworks and different methods have appeared to apply UD in different ways and contexts to achieve benefits over classical usability.

Sustainability achievement is a significant but dormant need in today's society and different attempts from diverse research domains often struggle to become successful in solving this issue. Innovation towards sustainability is not an exception in this regard either. Therefore, our addressed research question is answered here by stating, "Organisation's design strategy can be enhanced by using UD by attaining a better understanding of the different innovation levels". Further investigation, research and empirical evidence are therefore required to analyze the viability of innovation triggering with the help of UD. The success of using UD towards innovation and sustainability achievement would depend on different factors e.g. type of tool selected for analysis; type of method developed and different biases that needs to be avoided, etc. Thus, for UD to act as an origin for promoting sustainability innovation it cannot only be a unidirectional simple subject matter, rather it should be thought as a bidirectional complex issue. For example, UD itself might not be sustainable, but while used as a tool in design, it could be used to promote sustainability actions within different fields of research namely information system design. These subjects are worth exploring through future research.

However, measuring or benchmarking innovation is a very complex phenomenon e.g. comparing and ranking innovativeness. Whether the use of the proposed framework with the help of UD will trigger innovation for sustainability is therefore a very difficult question to ask and even delicate to empirically measure. On the other hand, it is very important and needful to capture the benefits from the innovation and measuring the whole innovation process. Tidd and Bessant [37] suggested that more strategies are therefore required for encouraging risk taking and innovation for capturing social and economic benefits of innovation. The way UD was used to show the innovation level trigger in our proposed framework could be a key to this argument, since the framework is intended to promote sustainable ac- 
tions and is based on the economic, social and environmental pillar. Therefore, one of the important next steps of this research would be to find appropriate cases of innovation and sustainability and then utilize the proposed framework to analyze changes in innovation trigger. A proper innovation management capability could then be developed within the context of specific design.

Also interesting to investigate further, is how organisationcentered or firm-specific innovation and industry-centered innovation differ, while practicing the proposed innovation level framework for sustainability. Different types of return on investment could then be scrutinized from the sustainability perspective to conclude what innovation type could be preferable to be easily triggered for sustainability. Another long-term ambition of this framework could be to forecast innovation where an existing business plan could be benefited and developed further by anticipating the use of available resource for adopting innovation and thereby sustaining the organisation over time. Therefore, further case study analysis and research are required to advance the idea of our proposed framework.

\section{CONCLUSION}

Innovation has always been a fundamental approach taken by organisations to gain a competitive advantage and become successful in the market. At present, innovation is not only limited within the scope of introducing new technologies, but it is seen from a comprehensive perspective to play a crucial role for several intensive social phenomena of the society. Sustainability through design is one of such phenomenon that this paper addressed. While UD is closely related to sustainability, its expanded concept can play a central role in understanding appropriate innovation levels and in deciding the right design strategies for the organisations.

The proposed innovation level framework therefore opens new opportunities to look upon sustainability achievement through design from a different viewpoint. Practicing UD as an integrated property of design by mainstreaming it would also open new challenges, which are worth exploring to add further support into the new dimension of UD together with future studies of sustainable HCI.

\section{REFERENCES}

[1] Barney, J. Firm resources and sustained competitive advantage. Journal of management, 17(1), 1991, 99-120.

[2] Bower, J. L., and Christensen, C. M. Disruptive technologies: catching the wave. Harvard Business Review, 73(1), 1995, 43-53.

[3] Chandy, R. K., and Tellis, G. J. Organizing for radical product innovation: The overlooked role of willingness to cannibalize. Journal of Marketing Research, 35(4), 1998, 474-487.

[4] Chandy, R. K., and Tellis, G. J. The incumbent's curse? incumbency, size, and radical product innovation. Journal of Marketing, 64(3), 2000, 1-17.

[5] Christensen, C. M. The Innovator's Dilemma: When New Technologies Cause Great Firms to Fail. Harvard Business School Press, Boston, 1997.

[6] Christensen, C. M., Baumann, H., Ruggles, R., and Sadtler, T. M. Disruptive innovation for social change.
Harvard Business Review, 84(12), 2006, 94-101+163.

[7] Clemens, R. V., and Doody, F. S. The Schumpterian System. Addison-Wesley, Cambridge, USA, 1950.

[8] Coccia, M. Classifications of innovations: Survey and future directions. Working Paper 2/2006. Ceris-Cnr, 2006.

[9] DiSalvo, C., Sengers, P., and Brynjarsdóttir, H. Mapping the landscape of sustainable hci. In Proceedings of the SIGCHI Conference on Human Factors in Computing Systems (CHI '10), ACM, New York, 2010, 1975-1984.

[10] DiSalvo, C., Sengers, P., and Brynjarsdóttir, H. Navigating the terrain of sustainable hci. interactions, 17(4), 2010, 22-25.

[11] Elkington, J. Towards the sustainable corporation: Win-win-win business strategies for sustainable development. California Management Review, 36(2), 1994, 90-100.

[12] Fog, B. J. Persuasive technology: Using computers to change what we think and do. Morgan Kaufmann, San Francisco, 2003.

[13] Freeman, C. The nature of innovation and the evolution of the productive system. In Technology and productivity: the challenge for economic policy. OECD, Paris, 1991.

[14] Freeman, C. A green techno-economic paradigm for the world economy. In The Economics of Hope, C. Freeman, Ed. Pinter Publishers, London, 1992, 190-211.

[15] Friedman, K. Theory construction in design research criteria: Approaches, and methods. Design Studies, 24(6), 2003, 507-522.

[16] Garcia, R., and Calantone, R. A critical look at technological innovation typology and innovativeness terminology: A literature review. Journal of Product Innovation Management, 19(2), 2002, 110-132.

[17] Geels, F. W. From sectoral systems of innovation to socio-technical systems: Insights about dynamics and change from sociology and institutional theory. Research Policy, 33(6-7), 2004, 897-920.

[18] Gossett, A., Mirza, M., Barnds, A. K., and Feidt, D. Beyond access: A case study on the intersection between accessibility, sustainability, and universal design. Disability and Rehabilitation: Assistive Technology, 4(6) 2009, 439-450.

[19] Knight, K. E. A descriptive model of the intra-firm innovation process. Journal of Business, 40(4), 1967, 478-496.

[20] Markides, C. Disruptive innovation: In need of better theory. Journal of Product Innovation Management, 23(1), 2006, 19-25.

[21] Meyers, P. W., and Tucker, F. G. Defining roles for logistics during routine and radical technological innovation. Journal of the Academy of Marketing Science, 17(1), 1989, 73-82.

[22] Mustaquim, M., and Nyström, T. Design principles of open innovation concept - universal design viewpoint. In UAHCI. Design Methods, Tools, and Interaction Techniques for eInclusion, C. Stephanidis and M. Antona, Eds., vol. 8009 of LNCS. Springer, Heidelberg, 2013, 214-223. 
[23] Mustaquim, M., and Nyström, T. Designing sustainable it system -from the perspective of universal design principles. In UAHCI. Design Methods, Tools, and Interaction Techniques for eInclusion, C. Stephanidis and M. Antona, Eds., vol. 8009 of $L N C S$. Springer, Heidelberg, 2013, 77-86.

[24] Mustaquim, M., and Nyström, T. Designing information systems for sustainability -the role of universal design and open innovation. In Advancing the Impact of Design Science: Moving from Theory to Practice, M. Tremblay, D. VanderMeer, M. Rothenberger, A. Gupta, and V. Yoon, Eds., vol. 8463 of $L N C S$. Springer International Publishing, Cham, 2014, 1-16.

[25] Mustaquim, M., and Nyström, T. Designing persuasive systems for sustainability -a cognitive dissonance model. In Proceedings of the European Conference on Information Systems (ECIS) 2014, AISeL, 2014.

[26] Mustaquim, M., and Nyström, T. Open sustainability innovation -a pragmatic standpoint of sustainable hci. In Perspectives in Business Informatics Research, B. Johansson, B. Andersson, and N. Holmberg, Eds., vol. 194 of $L N B I P$. Springer International Publishing, Cham, 2014, 101-112.

[27] Nidumolu, R., Prahalad, C. K., and Rangaswami, M. R. Why sustainability is now the key driver of innovation. Harvard Business Review, 87(9), 2009, 56-64.

[28] Norman, D. A., and Verganti, R. Incremental and radical innovation: Design research vs. technology and meaning change. Design Issues, 30(1), 2014, 78-96.

[29] Nyström, T., and Mustaquim, M. Sustainable information system design and the role of sustainable hci. In Proceedings of the 18th International Academic MindTrek Conference (AcademicMindTrek '14), ACM, New York, 2014, 66-73.

[30] Rogers, E. M. Diffusion of innovations, fifth ed. Free Press, New York, 2003.

[31] Schmidt, G. M., and Druehl, C. T. When is a disruptive innovation disruptive? Journal of Product Innovation Management, 25(4), 2008, 347-369.

[32] Schumpeter, J. A. Business Cycles: A theoretical, historical and statistical analysis of the Capitalist process. McGraw-Hill, New York, 1939.

[33] Schumpeter, J. A. Capitalism, Socialism, and Democracy. Harper, New York, 1942.

[34] Simon, H. The Science of the Artificial, third ed. MIT Press, Cambridge, USA, 1996.

[35] Stegall, N. Designing for sustainability: A philosophy for ecologically intentional design. Design Issues, $22(2), 2006,56-63$.

[36] Story, M. F., Mueller, J. L., and Mace, R. L. The Universal Design File: Designing for People of All Ages and Abilities, revised ed. NC State University The Center for Universal Design, 1998.

[37] Tidd, J., and Bessant, J. Managing Innovation: Integrating Technological, Market and Organizational Change, fifth ed. Wiley, 1998.

[38] Tushman, M. L., and Anderson, P. Technological discontinuities and organizational environments. Administrative Science Quarterly, 31(3), 1986, 439-465.

[39] World Commission on Environment and Development (WCED). Our Common Future. Oxford University Press, 1987. 